\title{
Momba'etéva
}

(Lo que es significativo, relevante)

Revista de Investigaciones en Ciencias Jurídicas, Sociales y Políticas

\section{DERECHO Y MUJERES AFRODESCENDIENTES EN ASUNCIÓN DURANTE EL SIGLO XVIII}

\author{
López Villagra, Edgardo Darío
}

Profesor Titular en Sociología, Cátedra "A”. Profesor Titular en Historia Constitucional Argentina, Cátedra "A”. Facultad de Derecho y Ciencias Sociales y Políticas. Universidad Nacional del Nordeste. Doctor en Historia de Americana (Universidad de Sevilla). Doctor en Derecho (Universidad Nacional del Nordeste). Director de PI CyT UNNE.

\section{Portillo, Nadia Carolina}




\section{RESUMEN}

El articulo avanza respecto a algunas reflexiones sobre el maltrato y la violencia que sufrieron las féminas afrodescendientes en Paraguay principalmente durante fines del siglo XVIII. A través del estudio de casos judiciales se vislumbra no sólo las relaciones interétnicas sino también la manera en que las instituciones españolas coloniales abordaban este tipo de temáticas.

\section{Palabras claves}

Maltrato, violencia, justicia colonial.

\section{Abstract}

The article advances with respect to some reflections on the mistreatment and violence suffered by Afro-descendant women in Paraguay mainly during the late eighteenth century. Through the study of judicial cases, not only the interethnic relations but also the way in which the Spanish colonial institutions approached this type of subject can be seen.

\section{Keywords}

Abuse, violence, colonial justice

RECEPCIÓN: 10/09/2019

ACEPTACiÓn: 15/02/2020

\section{INTRODUCCIÓN}

Marta Goldberg ha estudiado diversos casos en los que las esclavas requerían su libertad o cambio de amo, por malos tratos. Cabe resaltar que esta condición estaba contemplada en la Ley Novena, título VIII, Partida VII, que penaba al amo que ocasionara heridas a su esclavo (Alfonso El Sabio, 2004). Asimismo, esta norma se ratificaba en la Real Cédula de 1789, que recalcaba en el capítulo X, tanto para el caso de muerte como para las contusiones, heridas o mutilaciones:

\footnotetext{
"la pena correspondiente al delito cometido como si fuese libre el injuriado, confiscándose además el esclavo [...] y cuando el esclavo quedase inhábil para trabajar de resultas del castigo [...] deberá contribuir su dueño con la couta diario que se le señalase por la justicia para su manutención y vestuario por todo el tiempo de la vida del esclavo [...]” (s/a, 1839, 52).
} 
Además, el castigo podía implicar la pérdida del esclavo (que cambiaba de dueño) o la libertad del mismo (si hubiera quedado inválido). En este sentido, se puede hacer mención a un caso que se dio en 1785. En esta ocasión, la parda Francisca, esclava de Clara de Echenique,recurrió a la justicia para acusar a su ama de malos tratos. Su Defensor,Martín de Álzaga, presentó su alegato en auxilio de Francisca, quien se encontraba recluida en un hospital debido a la crueldad y tratos inhumanos recibidos por su propietaria (Cevasco, 2006). Varias personas aportaron sus testimonios del asunto, entre ellos, el médico que la había atendido, Gerónimo de Aréchaga, quien afirmó que en pocos días la esclava estaría recuperada de las heridas que sufría (tanto en los muslos como en las nalgas). Cabe resaltar que Francisca no sólo había sido azotada, sino que también estuvo atada a una escalera, y posteriormente encerrada durante tres días, con grillos y en ayuna, hasta que tuvo lugar su traslado al hospital.

Frente a este escenario compareció el ama, doña Clara Echenique (viuda del Coronel José Martínez), quien estaba patrocinada por el Licenciado Elizalde. La mujer, ante estas circunstancias, manifestó que había sido despojada de su esclava, y por lo tanto, interpuso una queja ante el Virrey para que se declarase el fuero y privilegio que le correspondía como viuda de militar. Mientras, pidió que se interrumpiera la causa hasta que se le diese curso a su pedido (trasladarlo al fuero militar) (Knecher, Panaia, 1994). Si bien el Defensor de Pobres, Álzaga, se opuso al pedido de doña Echenique, el Alcalde resolvió, en base a las observaciones del médico que atendió a Francisca, que ella:

"halla ya totalmente buena y sana del severo castigo [...] la entregará a la referida Doña Clara para que la sirva, previniéndola que no disponga de ella hasta la conclusión de esta instancia, ni menos que la castigue con la inhumanidad que el expediente manifiesta, bajo del concepto que de lo contrario se procederá a lo que haya lugar [... $]^{\prime}{ }^{1}$

Álzaga apeló para que Francisca no volviera con doña Clara debido a la calificada sevicia con que la atormentaba. No obstante, el Virrey (quien se consideraba competente para entender en la causa) le restituyó la esclava a doña Clara, luego de que esta manifestara no castigarla por lo pasado. Si bien Francisca imploró que la vendiesen en lugar de ser entregada a su ama, su propietaria tenía intenciones de llevarla a Córdoba, con la promesa de no darle "el más leve castigo". Fue por ello que el Virrey, el 12 de noviembre de 1785, finalmente le concedió a Clara el derecho de llevarse a la esclava, bajo el cargo de los ofrecimientos que hacía: 
“[... ] y apercíbase a la dicha esclava para que sirva a su Ama con la obediencia, sumisión y respeto a que está obligada bajo la más rigurosa pena a que diere lugar por su reincidencia, por cuyo medio y buena versación evitará las resultas que se teme, pues que sus excesos pasados ya se consideran suficientemente compurgados $[\ldots]]^{2}{ }^{2}$

En la lectura del expediente se puede observar que Francisca no obtuvo el papel de venta, se habría fugado en dos oportunidades, y una vez prendida y alojada en la Casa de Reclusión, fue remitida a doña Clara (Saguier, 1995).

En otro tipo de situaciones, como ser el deseo que contraer matrimonio, el amo podía otorgarle papel de venta, si él se oponía a esta unión. Con dicho papel, el esclavo podía buscar un nuevo propietario, quien habría de costear al amo anterior el precio estipulado. ${ }^{3}$ El problema que generalmente se suscitaba en estos casos era que el importe establecido por el amo era exageradamente alto, y por lo tanto, difícil de conseguir comprador. ${ }^{4}$ Es por esto que también se encuentran muchos expedientes en donde era muy alta la tasación y la esclava invocaba un valor inferior, aduciendo que había desmejorado su servicio u otros motivos (Isaola. 1975).

\section{HERMENÉUTICA JURÍDICA}

En los últimos años se ha despertado el interés por las fuentes judiciales debido a la riqueza y patrimonio que constituyen y aportan a los estudios socio-históricos (Mayo, Mallo, Barreneche, 1989). Desde la Edad Moderna se denomina fuentes del derecho a aquellos actos o hechos a los que el ordenamiento jurídico reconoce capacidad para crear derecho y que sirven para establecer y sistematizar procedimientos y disposiciones que producen normas. Los modos de formular las normas jurídicas que se sustentan en la

2. Ibídem.

3. Asunción, ANA, Sección Civil y Judicial, Vol. 2153, Núm. 6, Año 1806, "Demanda de Juan Antonio Penayo, contra María Agueda Pereira, sobre libertad de una esclava”.- Asunción, ANA, Sección Civil y Judicial, Vol. 2071, Núm. 4, Año 1739, "Sobre la libertad de una mestiza llamada Antonia hija de Sebastian José Sosa".

4. Para el caso de los valores excesivos impuestos por los dueños de esclavos, véase: Asunción, ANA, Sección Civil y Judicial, Vol. 1364, Núm. 11, Año 1805, "El Defensor General de Pobres, a nombre de Salvador (esclavo) por rebaja de precio”. -Asunción, ANA, Sección Civil y Judicial, Vol. 1897, Núm. 5, Año 1812, "E1 Defensor General de Pobres sobre precio de Parda esclava Margarita, de Doña Petrona Francia”.- Colombia, AGN, Fondo Colonia, Grupo Negros y Esclavos, Sección Antioquía, Serie Documentos Históricos, Tomo 31, Legajo 32, "El defensor general de menores Andrés Pastor, solicita que Josefa Rodríguez le dé un justo valor a su esclavo Andrés para que él compre su libertad".- Asunción, ANA, Sección Civil y Judicial, Vol. 2165, Núm. 21, Año 1793, "Demanda del Defensor de Pobres a nombre de Rafael esclavo de Luis Rojas, para que éste le cumpla la promesa que le hizo, de darle su libertad por el mismo valor". 
costumbre, la ley, las decisiones judiciales y la doctrina, así como también en la Constitución, los reglamentos, las ordenanzas y los principios generales del derecho (Levaggi, 2004).

En este contexto, las nuevas inquietudes hermenéuticas han llevado a la exploración y utilización del expediente judicial, que se ha constituido en observatorio del que han partido algunos de los más valiosos aportes de los últimos años. La visión de los expedientes judiciales ha variado en función a los enfoques desde los que se han encarado o por la utilización que se ha hecho de ellos como fuente de investigación. Tanto las causas entabladas en los tribunales seculares como en los eclesiásticos han sido el punto de partida para este tipo de trabajos históricos. Se trata de un tipo de fuente privilegiada, de alto valor a la hora de adentrarse en una sociedad determinada. Además, permite un acercamiento diferenciado a las clases marginales y a la percepción que el resto de la comunidad tenía sobre ellas. Estos recursos heurísticos permiten aprehender la sociedad no como un ente estático y dividido en estancos, sino como dinámico y en constante mutabilidad.

El Archivo Nacional de Asunción conserva innumerables fuentes manuscritas que permiten tener una visión bastante amplia del proceso esclavista en esa región del Virreinato del Río de la Plata. Este proceso muestra una faceta diferente luego de la Independencia del Paraguay, una mentalidad antiesclavista en donde se encontraban dos derechos en conflicto: la libertad del esclavo, y la propiedad del amo. Y si bien las condiciones históricas estaban a favor del esclavo, la consolidación de su libertad (lenta y progresiva) no se materializaría sino hacia la segunda mitad del siglo XIX (Rosal, 2002).

\section{Procedimiento judicial}

En toda Hispanoamérica, los esclavos podían denunciar a sus amos cuando éstos actuaban con crueldad. La Corte examinaba las acusaciones e iniciaba sumaria averiguación de lo ocurrido, así como también la examinación cuando los demandantes presentaban heridas por maltrato o síntomas de violencia física de cualquier tipo. Es decir, la Corte buscaba determinar si los amos habían incurrido en excesos y para ello consultaba a los testigos si tenían conocimiento de que el propietario hubiera maltratado al subyugado.

Iniciar una causa judicial no era tan simple como lo establecía la letra. En algunos casos, el esclavo debía buscar el momento oportuno para realizar la denuncia, sin que el amo tomara conocimiento de ese acto. Debía escaparse de su lugar de trabajo sin que el amo se enterara y presentar su demanda en un memorial. Luego, se daba conocimiento del asunto al Procurador General Protector de Esclavos para que lo defendiera, al tiempo que se nombraba a una autoridad local para que iniciara las averiguaciones pertinentes a la demanda. 
Los testigos eran una parte sustancial en los procesos. Éstos podían desmentir o ratificar las acusaciones. También los amos tenían derecho a presentar sus testigos con el mismo fin. Para Moisés Munive, el número de testigos que presentaba el amo era clave para que hablaran bien de él y exageraran el buen trato que practicaba para con sus esclavos (Munive, 2008). Aquí, se debe reconocer la difícil situación en la que se encontraban los esclavos, pues debían declarar en contra de sus amos quienes estaban presente, escuchando y observando, mientras lo hacían.

Finalmente, una vez realizada las investigaciones y obtenida la declaración de los testigos, se procedía a fallar sobre el asunto. Dos alternativas eran posibles: una sentencia a favor o una sentencia en contra del amo. En el primer caso, cuando la sentencia era en detrimento del esclavo, éste debía ser devuelto al amo quien podía "corregir" su conducta imponiéndole una pena moderada por haberlo difamado (Salmoral, 1994). Por el contrario, cuando se comprobaba la acusación, el esclavo debía ser vendido a un nuevo amo y en este caso se lo tasaba para determinar su justo valor. Además, el amo debía pagar una multa a la Real Hacienda y costear los gastos de manutención del esclavo hasta concretada su venta. ${ }^{5}$ En este sentido se pueden mencionar los casos de los esclavos que solicitaban ser vendidos. Como Francisco, quien pidió en 1748 el papel de venta. O el esclavo Ventura, que se involucró en una situación similar luego de la muerte de su propietaria. ${ }^{6}$ En estas circunstancias, también podía mediar el Defensor de Pobres para lograr las peticiones de los esclavos. Tal como sucedió con el esclavo Salvador, quien contaba con la ayuda del defensor para lograr la venta. ${ }^{7}$

5. Asunción, ANA, Sección Civil y Judicial, Vol. 2056, Núm. 2, Año 1771, "Querella de Juan Alberto (pardo), contra Pedro Pablo Rojas sobre venta de una esclava”.- Asunción, ANA, Sección Civil y Judicial, Vol. 2008, Núm. 12, Año 1810, “Demanda de Juan de Dios Melo contra Juana Rosa López, sobre desalojo de una esclavita".- Asunción, ANA, Sección Civil y Judicial, Vol. 1959, Núm. 11, Año 1720, "Información de utilidad para la venta de un esclavo menor".- Asunción, ANA, Sección Civil y Judicial, Vol. 1965, Núm. 7, Año 1770, "Demanda de Gregorio Navaja por la venta de un esclavo".- Asunción, ANA, Sección Civil y Judicial, Vol.2179, Núm. 7, Año 1723, "Pedimento de venta de su persona Silveria esclava de Maria Ramírez”.- Asunción, ANA, Sección Civil y Judicial, Vol. 1362, Núm. 14, Año 1735, "Duarte Josefa, vende una esclavita".

6. Asunción, ANA, Sección Civil y Judicial, Vol. 1306, Núm. 6, Año 1748, "Francisco Pardo (esclavo) solicita ser vendido".- Asunción, ANA, Sección Civil y Judicial, Vol. 1956, Núm. 5, Año 1794, "Expediente de diligencia sobre la venta del esclavo ventura, perteneciente a la testamentaria de Juana Escobar que fue promovida por el heredero de Juan Miguel Martínez".

7. Asunción, ANA, Sección Civil y Judicial, Vol. 2249, Núm. 2, Año 1803, "Demanda del defensor General de Pobres a favor de Salvador, esclavo de marcos Barrientos, para su venta". 


\section{LOS EXPEDIENTES JUDICIALES}

Los expedientes judiciales son algo más que una sucesión de reclamaciones, contestaciones de demandas, confesiones, testimonios y sentencias. Profundizando en la información que aporta cada caso, y en función de lo que se pretenda encontrar, es posible rastrear mayores elementos que el asunto puntual que es objeto del litigio. Constituye la expresión de un conflicto: una obra de teatro contada por sus propios protagonistas, por aquellos que se encontraron casualmente involucrados en el incidente. A través del proceso se muestra cómo cada actor decodificaba la realidad, cómo manipulaba la norma a su favor y cómo buscaba las distintas maneras de resolver las diferencias, hasta llegar, si el litigio no podía ser resuelto con los recursos con que se contaba, a traspasar los límites de lo privado, a la búsqueda de una solución a sus problemas (Tedesco, 2015).

Es así que se expresan la relación entre la norma y el comportamiento, entre lo que se prescribe y aquello que se acata: el hecho de que exista una ley que fije determinadas obligaciones no significa que sus destinatarios estén de acuerdo y que las prescripciones se cumplan. Del desajuste entre lo que se intenta imponer y lo que se suscita en la práctica, da cuenta el conflicto judicial, que ayuda a registrar hasta qué punto se ha producido en los individuos la interiorización de las disposiciones legales vigentes y hasta dónde, un proceso de marginación del orden legal establecido. Una de las formas de medir el ajuste entre lo prescripto y lo efectivamente cumplido es a través de los pleitos judiciales.

La relación entre la norma y la realidad, legislación y práctica, ha sido uno de los puntos en lo que se han concentrado mayormente los historiadores del derecho. Esta constatación ha llevado a la reflexión acerca de la posibilidad de aplicación de las leyes en los confines indianos, o por el contrario, de la imposibilidad de trasladar normas dictadas en otras épocas, otros ámbitos y otras motivaciones.

Se asiste así, a través del expediente judicial, a la comprobación del nacimiento de un pluralismo normativo, de una diversidad de fuentes del derecho que enriquecen el mundo jurídico (Rangel, 2011). Al mismo tiempo, el litigio y las formas que tienen el apartado judicial para resolverlos trasunta las concepciones del poder, las relaciones de éste con los justiciables, y, en definitiva, demuestra una forma de asentamiento del Estado (Kluger, 2004).

El enfrentamiento judicial trasluce, paralelamente a las invocaciones de leyes, cédulas y provisiones, la invocación y aceptación de ciertos principios jurídicos, el peso del antecedente (praxis judicial) y el papel de la doctrina judicial. De ahí que no resulte difícil detectar su orden judicial que se constituye en instrumento de control social, cuyos integrantes cargan con el peso de mantener la paz y la justicia. Estos objetivos se presentan como necesarios, habida cuenta de las características que, también a través de los expedientes judiciales, se conoce acerca de la vida social indiana en los siglos de 
dominación imperial. Un escenario en el que nunca faltaron pleitos y violencias cotidianas. Era así como los tribunales tenían la responsabilidad de castigar los delitos y pecados públicos, de enmendar las costumbres y de suprimir los escándalos.

Sin embargo, la fuente judicial no puede convertirse en el único instrumento heurístico para entender la sociedad ni tampoco pueden hacerse generalizaciones a partir de los casos particulares. No obstante, se debe reconocer que permite acceder a la vida cotidiana y al imaginario de determinados grupos sociales a través de la aplicación del derecho indiano vigente. En especial, a la cotidianeidad de la vida de esa mayoría de población que no formaba parte del aparato estatal ni de la elite económica, que era la que solía dejar documentos escritos (Anzoategui, 1997).

Generaciones de historiadores han privilegiado el estudio de las leyes promulgadas por el Consejo de Indias y otros órganos superiores del Estado. Menos atención recibieron las regulaciones dictadas por los órganos locales de poder, que reflejaban mejor los intereses de los dueños de esclavos en las colonias. Estos autores a menudo analizaron el derecho positivo, sin hacer referencia a las condiciones sociales en las que el mismo era aplicado, o a las experiencias e iniciativas de los esclavos, los amos y las autoridades coloniales (Alonzo, 1983).

Los distintos sumarios existentes consultados en el Archivo Nacional de Asunción demuestran una considerable cantidad de casos en los que miembros de la casta negra eran maltratados. Los continuos y salvajes maltratos a los que eran sometidos, junto a condiciones miserables de vida, justificaban en algunos casos la decisión final de quitarse la vida (Fraginals, 2006).

Cabe aclarar que muchos de los casos que fueron tomados para este trabajo no tienen una resolución final pero deben tenerse en cuenta en lo que respecta al relato y la descripción como herramienta para entender e interpretar la realidad de la época así como la visión misma de los personajes implicados en esta comunidad. Esa falta de resolución de los pleitos, se debe a la destrucción y al deterioro de los fondos documentales aunque no es menos cierto que también se debe a la época crítica en la que estos documentos fueron producto del saqueo por parte de las tropas brasileñas durante la guerra de la Triple Alianza (Urquijo, 1996). No obstante han podido reconstruirse que de alguna u otra manera reflejan aspectos de la cotidianeidad de la vida de aquellas mujeres que habitaron el Paraguay.

Una segunda aclaración corresponde al tema de las distinciones de casta. En el Paraguay en numerosas oportunidades se tomaban como sinónimos la referencia sobre los pardos, negros y esclavos, generando una confusión. Del mismo modo, se debe aclarar que el término "castas" fue altamente peyorativo porque fue retomado de las acepciones medievales negativas del vocablo, vigentes en el sociedad castellana del siglo XVIII. 
Designaba por un lado, el tipo de relación sexual animal o promiscua y, por otro, implicaba que los hijos heredaban los vicios de los padres además del aspecto físico (Chavez, 1998).

Los hombres y las mujeres que eran englobados en el término de casta eran descendientes de africanos, ya fueran mulatos, zambos o cuarterones, entre otros, y por ende se los vinculaba a la condición de esclavitud (Alonso, 1974). Incluso en la normativa de 1764 para la declaración de mestizos se observa que castas era sinónimo de carencia de honor (Chavez, 1998).

Estas formas históricas de diferenciación en la estructura social paraguaya revelan de qué manera la construcción de una caracterización e identificación étnica de la población marcó durante más de trescientos años una forma estamental de organización social, en la que la prosapia y las instituciones jurídico-políticas delineaban la pertenencia a los distintos grupos sociales. Sin embargo, tras la guerra de la Triple Alianza, las diferencias sociales ya no se ajustarían a la ascendencia étnica.

\section{Pleitos judiciales}

La invisibilidad característica de los negros durante décadas ya ha expirado, y actualmente sus descendientes forman una parte esencial de la sociedad contemporánea de muchos lugares de Hispanoamérica, entre ellos, Paraguay (Peñaloza, 2007). Los abusos cometidos contra los esclavos o los procesos en los que éstos estaban incriminados están categorizados de acuerdo al tipo de delito o demanda que se trata. En efecto, esto induce a reflexionar sobre la parte de la realidad de la historia social de los afrodescendientes de Paraguay, haciendo énfasis en determinados expedientes y desplegando de esta manera la humillación, la desconsideración y la deshumanización de los esclavos.

En el período tardocolonial, se puede afirmar que eran habituales los malos tratos y las humillaciones sobre los pardos, negros y mulatos por parte de representantes de la autoridad colonial, algunos con especial saña y crueldad. Los oprimidos, en numerosos casos preferían fugarse para evitar dichos maltratos, otras veces ofendían a sus amos, incineraban las huertas u otras posesiones, o tenían hijos con sus amos, entre otros (Munive, 2008). Otra salida para los esclavos era demandarlos por exceso en el castigo físico. Sin embargo, como sostiene Munive, ir a juicio no era sinónimo de ganar el pleito, ya que muchas variables que intervenían en el asunto podían opacar la ilusión de una victoria jurídica. ${ }^{8}$

8. Ibídem. Págs. 97-116. 
Un caso tuvo lugar en Colombia en el año 1789 cuando un médico denunció a Juana María Rodríguez por intentar envenenar a sus amos. ${ }^{9}$ Esta era otra de las alternativas que contemplaban algunos de los siervos para salirse del yugo de sus amos. En esta oportunidad, Juana María había alimentado a sus propietarios con comida envenenada con unas hierbas que ella misma había preparado. La familia, al sentirle un sabor extraño no terminó de ingerir las comidas. En razón de ello, el señor inspeccionó la casa, encontrando la botella que contenía el veneno al cual le realizó un estudio para corroborar aquello que ya sabía. Al comprobar que aquella agua contenida en la botella podía causar algún daño a su salud, inició la causa criminal contra su esclava.

Diferentes testigos dieron cuenta de la existencia del veneno y de los efectos corrosivos que este podía tener en cualquier persona que lo consumiera. Explicaban los expertos que la familia no sufrió daños gracias a que no terminaron de comer todo y a que consumían leche para quitarse el sabor amargo que les quedaba en la boca. De ese modo estaban opacando los efectos del veneno casero.

Juana María había pretendido asesinar a sus dueños. Según se sabe, ella intentó que sus amos José Sorel y Micaela Sánchez tuviesen un trato más digno hacia ella, pero sin mucho éxito. Fue por ello que no encontró otra manera de librarse del mal que le pesaba más que por una vía criminal. Lo que se puede observar en este caso es la resistencia viva a la esclavitud.

$\mathrm{Y}$ es que los derechos del esclavo, y por supuesto los del liberto, eran reconocidos de manera explícita en las normas jurídicas, así como tutelados eficazmente por el sistema de garantías castellano-indiano. La protección que recibían estas personas estaba fundada en las leyes, pero la realidad de la práctica judicial las volvía oscuras. La apelación a mecanismos legales en la segunda mitad del siglo XVIII fue calificado por Fernando de Trazegnies como el "despertar jurídico" de la población esclava (Trazegnies, 1989). De acuerdo a este autor, la capacidad de adaptación y resistencia de la población negra se marcaría profundamente en el período tardocolonial. ${ }^{10}$

Los conflictos entre castas como el caso anterior no eran los únicos que llegaban a un proceso judicial. Es posible vislumbrar también los procesos judiciales por situaciones

9. Colombia, Archivo General de la Nación, Sección Colonia. Negros y esclavos de Bolívar. Tomo 9, folio 530. Citado en Moisés Munive Contreras, "Resistencia estática: los negros colombianos contra la esclavitud: Cartagena y Mompox, siglo XVIII”, Tiempos Modernos, Núm. 14 (2006).

10. En relación a esto, Alberto Flores Galindo afirma que, tras tres siglos de dominación colonial "los esclavos adquieren algunos derechos (...) Humboldt enumera cuatro: buscar un mejor amo (generalmente con anuencia del anterior), casarse según su gusto (aunque requerían la autorización del propietario), comprar su libertad y poseer bienes" $(1984,18)$. 
de violencia doméstica que tenían lugar entre los mismos protagonistas de un matrimonio de negros. ${ }^{11}$ Tal es el caso del 20 de marzo aproximadamente del año 1774 cuando se inició sumaria a un pardo de nombre Ramón por haber herido a su mujer llamada Francisca. ${ }^{12}$ Al parecer, Francisca era una mestiza del servicio del Sargento Mayor Don Sebastián de León y Zárate. El documento que deja registro de este caso está sumamente dañado, lo cual dificulta la reconstrucción de los hechos. No obstante se hará un esfuerzo por delinear los acontecimientos más relevantes.

Según un testigo llamado Pedro Regalado Martínez, Ramón le desquitó un garrotazo a su mujer Francisca, golpe que la dejó postrada en el piso e inconsciente. El pardo entonces aprovechó para huir con un arma de fuego en la mano. Pedro no pudo aportar más datos. Entonces se mandó a comparecer a Francisca, una criada de Don Sebastián de León a quien se le tomó juramento en nombre del Señor. Su declaración se encuentra incompleta por los daños del documento. De igual modo, es posible entender que afirma no saber por qué motivo Ramón lastimó a su mujer y que no se encontraba en el lugar al momento del hecho.

A raíz de ello, el Juez Comisionado mandó a que se practiquen las pertinentes diligencias para encontrar a Ramón y apresarlo dado que para ese momento se encontraba prófugo. Una vez que lo hallaran, debía ser remitido al Señor Gobernador Capitán General para que su Señoría determinara lo que fuera justo.

El tiempo se transformó en un enemigo. Era urgente encontrar al responsable pues Francisca no logró sobrevivir. Fue sepultada en la capilla de Luque. Esta circunstancia agravó la situación del reo prófugo por lo que se lo llamó por edictos y pregones públicos dejándose copias en lugares concurridos para hacer extensiva la noticia. Se publicó también en los portales del cuerpo de guardia. Sin embargo, a pesar de tres edictos, el pardo siguió desaparecido. No obstante esta situación, se mandó a ratificar sus declaraciones a los testigos.

En vista de ello, el Promotor Fiscal y Defensor de la Real Hacienda:

"En vista de los autos criminalmente dejados en ausencia y por rebeldía de Ramón pardo esclavo de Don Sebastián de León, por la muerte que ejecutó a su mujer en el Valle de Tapua- Francisca parda libre del mismo servicio, ante vuestra Merced alegando de bien

11. Colombia, AGN, Fondo Colonia, Grupo Negros y Esclavos, Sección Santander, Serie Documentos Históricos, Tomo IV, Legajo 4, Lorenzo Navas, vecino de Girón, su denuncia criminal contra Juan Patricio, Julian Matias y Francisco, sus esclavos, por una paliza que le dieron en su hacienda de Rionegro".

12. Asunción, ANA, Sección Civil y Judicial, Vol. 1435, Núm. 9, Año 1774, “Sumaria a Ramón pardo por herir a su mujer Francisca". 
probado dice: que el inhumano atroz delirio de dicho esclavo Ramón plenamente se halla justificado en la serie de los autos, y por ello incluso en la pena capital de que es digno y meresedor: que a más del plena justificación constante en el proceso acredita o acredito el cometido delito la fuga, que a hecho dicho agresor, que usando de rebeldía y untumasia no ha querido presentarse $[\ldots]^{\prime}{ }^{13}$

La justicia se esforzó por encontrar una solución, ya que la gravedad del caso lo merecía. Tal fue así que el fiscal pidió la pena capital para Ramón. Éste, no sólo se convirtió en homicida tras la muerte de Francisca sino que además, al no presentarse ante la justicia, estaba implícitamente negándose a ella. Fué por ello que, finalmente, se decidió que "el dicho reo actor (es) digno de pena capital, y en su conformidad le devia condenado en muerte en horca impública forma". ${ }^{14}$

La pena capital era totalmente esperada, pues en la Partida VII, Titulo VIII, Ley II se estipulaba la pena de homicidio. No obstante, se debe señalar que el pardo Ramón siguió desaparecido por lo que se desconoce si llegaron a encontrarlo y a ejecutarlo. Podría pensarse que se fue de la ciudad e imaginar de qué vivió, siendo que era un esclavo, de lo que se presume no tenía muchas pertenencias o ganancias. Nótese un elemento más: el garrote, elemento con el cual se lastimó a la mujer, debe recordarse que los negros tenía prohibido poseer armas, por lo que era común la utilización de este tipo de herramientas para lastimar a otros.

Resulta interesante hacer referencia a un caso más, el mismo tuvo lugar el 2 de diciembre de 1805, en el partido de Bayue (jurisdicción de Asunción) cuando Vargas Luis abrió sumaria contra Alvarenga Francisca por maltratar a una esclava. ${ }^{15}$ Según la denuncia, la esclava se había ido al pozo a buscar agua cuando aparecieron varias mujeres con el único objetivo de hacerle daño con suma saña y maldad.

E1 Juez de Comisión se presentó para examinar a la mulata herida y descubrir qué pasó. Luego le tomó declaración. La mujer confirmó que fue aporreada cuando se fue a buscar agua al pozo. Según su relato, le aparecieron Doña Francisca Xaviera, su hija María Ana y María del Carmen y otra niña menor de edad. Ana la tomó del cabello, la madre se le arrimó con un palo y la comenzó a golpear en la cabeza. Luego, llegó otra mujer llamada Bárbara Castillo a ayudarla, la tomó por el brazo y empezó a forcejear con las mujeres que la lastimaban, estrujándola y apaleándola por un buen rato. En aquel momento, llegó

\section{Ibídem. \\ 14. Ibídem.}

15. Asunción, ANA, Sección Civil y Judicial, Vol. 1384, Núm. 18, Año 1805, "Vargas Luis Contra Alvarenga Francisca por maltrato de una esclava”. 
un mozo llamado Juan de la Cruz Aguilera que pidió ayuda a Don Joseph Vargas con Salvador Coronel y Juan Bautista Coronel que acudieron al socorro. Los tres la hallaron siendo maltratada e intentaron frenar los maltratos separando a las mujeres.

Para comprender lo sucedido, se le preguntó si sabía el motivo por tal castigo. Claro estaba que la mulata sólo podía intuir los motivos pues no sabía a ciencia cierta por qué la lastimaron. ${ }^{16}$ No obstante declaró que el origen lo encontraba en un episodio que había ocurrido la semana anterior cuando pasando por la casa de Doña Francisca Xaviera, la oyó a ella y Doña Gregoria Castillo hablando mal de su amo. Ante ello, la mulata mostró cierta antipatía que pudo haber generado recelo por parte de las otras dos mujeres. Agregó que anteriormente María Ana la había abofeteado delante de Don Pedro Agüero.

A modo de reconstruir la historia y los motivos del maltrato, se le tomó declaración al Coronel Don Salvador que contó que se encontraba en la casa de Doña Asencia Aguilera cuando llegó Juan de la Cruz Aguilera a dar la noticia de lo que sucedía en el pozo. Se dirigieron hacia allá y hallaron a Francisca agarrándole del cabello a la esclava y dando remesones mientras la hija, por detrás, la tomaba del cabello con una mano y con la otra le daba puñetes hasta que llegó Vargas que pudo separarlas, aunque con dificultad. No obstante, no sabía el motivo que ocasionó el aporreo. Tras las declaraciones, comparecieron también Juan de la Cruz Agüero, Don Bartolomé Castillo y Don Pedro Agüero. Los tres no hicieron más que confirmar los hechos de maltrato en el pozo aunque ninguno pudo determinar los motivos.

Todas las declaraciones se elevaron al Superior Juzgado del Señor Gobernador Intendente para que determinara una pena correspondiente. Se dispuso que cada una de las agresoras debían pagar 4 reales a la mulata. Se les advirtió que si no corregían su conducta podrían ser llevadas a la cárcel, en donde serían castigadas. Pero cuando fueron a dar la sentencia a las agresoras, las mismas ya no se encontraban en su casa. Según se sabía, un día después del juicio habían salido y no regresaron más. Por este motivo, se hizo comparecer a Doña María Antonia Castillo y su hija Bárbara, ambas cómplices de la fuga. Sin éxito en capturar a las mujeres, se le aplicó una multa de 6 reales y medio que tuvo que pagar a la esclava. Además se le advirtió que debía corregir la conducta de su hija para que en un futuro no reincidiera en semejante exceso.

16. En relación a los castigos de los amos, se puede consultar también a Jean-Pierre TARdieu (2006, 317-358). 


\section{CONCLusiones}

Los diferentes relatos proporcionan una información valiosísima sobre la vida colonial. A través de ellos, se ha podido observar la fidelidad de los esclavos a sus amos y viceversa, al tiempo que los conflictos domésticos entre cónyuges no hicieron distinción de casta. Por otro lado, cuando se trata de abusos de los colonos hacia las demás castas no se estipularon penas o castigos, al menos que hayan quedados registrados lo cual otorga datos sobre la asimetría de poder entre las personas más allá de que se buscara contemplar la igualdad de la ley y los buenos tratos.

Resulta interesante señalar que la pena de multa, más allá del monto, fue un recurso corriente para satisfacer las necesidades del erario real, de la administración de justicia y aun para recompensas de los denunciadores de los crímenes. Las penas que ingresaban a la real hacienda recibían el nombre de penas de cámara (para la cámara del Rey) (Porras Arboledas, 2003).

Por último, no se debe perder de vista que, en un principio, los esclavos necesitaban la autorización de sus amos para estar en juicio; no obstante, siempre que la protección de sus intereses lo exigiera, la ley les habilitaba para ello. En las causas en las que los esclavos eran una de las partes, se aplicaban las reglas ordinarias de la competencia. Sin embargo, cuando lo que se demandaba era la libertad, como causa privilegiada que se consideraba, caía bajo la jurisdicción de las reglas de la Audiencia.

Tanto la legislación castellana como la indiana, se inspiraban en los principios del humanismo cristiano, reprimiendo los excesos de los amos y brindando a los esclavos, garantías de buen trato (Tau, 1985). Entre otras normas, se castigaba las heridas mortales de los amos a sus esclavos con la pena del homicida, y la Real Cédula del 31 de mayo de 1789 reiteraba en el capítulo $\mathrm{X}$ que, en esos casos, y en otros de contusiones, heridas y mutilaciones, debía imponerse a los amos y mayordomos "la pena correspondiente al delito cometido, como sifuese libre el injuriado"(Salmoral, 1996). Además, el esclavo ante los malos tratos, podía cambiar de amo, pero si había quedado inválido, tenía acceso directo a la libertad. La misma Cédula preveía la acumulación al anterior castigo de penas pecuniarias, de las que una tercera parte debía engrosar una caja de multas; pero en la práctica, no parecen haberse impuesto las multas, ni menos organizado la señalada caja. No se han encontrado en los archivos consultados la aplicación de estas multas (Mallo, 1991).

Al tratarse de un bien material, objeto del derecho, la ley 6, de título XXI, de la Partida IV, decía que el señor tenía el llano poder sobre su esclavo para hacer de él lo que quisiese, según el concepto romano, aunque aclarando a renglón seguido que no lo debía matar, ni lastimar, y ello a pesar de que le hubiese dado motivos. Las únicas faltas que autorizaban al amo a aplicar la máxima pena a sus esclavos eran las derivadas de encontrarlos con su mujer o hijas o causas semejantes. 
Finalmente, se debe reconocer que las causas judiciales registradas se corresponden con un porcentaje mínimo al verdadero maltrato que existía hacia los siervos. Igualmente, el procedimiento judicial era controlado por los mismos españoles de donde se desprende que, al ser una minoría, muchas veces estaban emparentados o relacionados con los propietarios de los esclavos (Munive, 2008). De allí, que en la práctica se mantuviera el tratamiento indigno y represivo. ${ }^{17}$

\section{Bibliografía}

Tardieu,JP. (2006). El negro en la Real Audiencia de Quito (Ecuador). Ss. XVI-XVIII. Quito: Institut français d'études andines, Cooperazione Internazionale (COOPI), AbyaYala, 2006.

Lavallé, B. (1994). "Aquella ignominiosa herida que se hizo a la humanidad: el cuestionamiento de la esclavitud en Quito a finales de la época colonial”. En Procesos, Revista Ecuatoriana de Historia, (6), 23-47.

Alonso, V.(1974). "Algunas ideas sobre la esclavitud y su investigación”. Bulletin de l'Institut Historique Belge de Rome, XLIV.

Alonzo, M. (1983). Un jurista indiano: Juan Antonio Torquemada. En Justicia, Sociedad y economía en la América Española, Valladolid: Casa-Museo Colón.

17. En relación a los abusos cometidos hacia el colectivo negro, se puede consultar los siguientes casos: Asunción, ANA, Sección Civil y Judicial, Vol. 2020, Núm. 9, Año 1806, "Queja del esclavo Ramón Alberto contra Pedro Hurtado sobre maltrato”.- Asunción, ANA, Sección Civil y Judicial, Vol. 1384, Núm. 18, Año 1805, "Vargas Luis contra Alvarenga Francisca Javiera, por maltrato a una esclava”.- Asunción, ANA, Sección Civil y Judicial, Vol. 2251, Núm. 5, Año 1778, "Demanda del pardo Pablo Cabañas, contra su ama Felipa Cabañas, por maltrato".Colombia, AGN, Fondo Colonia, Grupo Negros y Esclavos, Sección Antioquía, Serie Documentos Históricos, Tomo 3, Legajo 34, "El Procurador general José María Ortíz solicita que se le permita cambiar de amo a Isabel por el maltrato que le da el actual Tomás Berrío”. 
Kluger, V. (2004). "La historia de la familia colonial iberoamericana como tema de investigación interdisciplinario. Algunos aportes de las últimas décadas”. En Revista de Historia del Derecho (32).

Knecher, L. y Panaia, M. (1994). La mitad del pais: la mujer en la sociedad argentina. Buenos Aires: Centro Editor de América Latina.

Mallo, S. (1991). “La libertad en el discurso del estado, de amos y esclavos, 1780 - 1830”. En R.H.A. (112).

Mayo, C., Mallo, S. y Barreneche, O. (1989). "Plebe urbana y justicia colonial. Las fuentes judiciales. Notas para su manejo metodológico”. En Estudios e Investigaciones (1).

Munive, M. (2008). "Blanco seguro: el maltrato a los esclavos en Cartagena y Monpox durante el siglo XVIII". En Procesos Históricos, 7 (13).

Peñaloza, F. (2007). "Mapping Constructions of Blackeness in Argentina”.

Porras, P. (2003). E1 Ordenamiento de Penas de Cámara de Enrique III (1400). Un nuevo manuscrito. En Cuadernos de Historia del Derecho (10).

Rangel, F. (2011). Entre la libertad y la esclavitud: Dominguez Pérez en el litigio por su libertad y la de sus hijas. Cartagena: Universidad de Cartagena.

Rosal, M. (2002). La trata de negros y su incidencia en la salud de las poblaciones hispanoamericanas. El caso del Río de la Plata hacia el final del lapso colonial. En Idea Viva (13).

S/a,(1839). Compendio de la legislación y jurisprudencia española. Madrid: Librería de García.

Saguier, E. (1995). La fuga esclava como resistencia rutinaria y cotidiana en el Buenos Aires del siglo XVIII. En Revista de Humanidades y Ciencias Sociales, 1 (2).

Salmoral, M. (1994). Sangre sobre piel negra. Quito: Ediciones Abya - Yala.

Tau, V.(1985).El 'juicio de las leyes civiles' de Lope de Deza.Una obra crítica y reformadora en tiempos de Felipe III. En Revista de Historia del Derecho, (13).

Tau, V. (1997). Nuevos horizontes en el estudio histórico del Derecho indiano. Buenos Aires: Institutos de Investigaciones.

Tedesco, I. (2015). El acusado en el ritual judicial. Buenos Aires: Ed. Didot.

Trazegnies, F. (1989). Ciriaco de Urtecho: litigante por amor. Reflexiones sobre la polivalencia táctica del razonamiento jurídico. Lima: PUCP. 